\title{
Heat Transfer Model of Hyporthermic Intracarotid Infusion of Cold Saline for Stroke Therapy
}

\author{
Matthew A. Neimark, Angelos-Aristeidis Konstas, Andrew F. Laine, and John Pile-Spellman
}

\begin{abstract}
A 3-dimensional hemispheric computational brain model is developed to simulate infusion of cold saline in the carotid arteries in terms of brain cooling for stroke therapy. The model is based on the Pennes bioheat equation, with four tissue layers: white matter, gray matter, skull, and scalp. The stroke lesion is simulated by reducing blood flow to a selected volume of the brain by a factor of one-third, and brain metabolism by $50 \%$. A stroke penumbra was also generated surrounding the core lesion (blood volume reduction $\mathbf{2 5 \%}$, metabolism reduction $20 \%$ ). The finite difference method was employed to solve the system of partial differential equations. This model demonstrated a reduction in brain temperature, at the stroke lesion, to $32{ }^{\circ} \mathrm{C}$ in less than 10 minutes.
\end{abstract}

\section{INTRODUCTION}

$\mathrm{S}$ troke is a disease whose incidence exceeds 700,000 new and recurrent cases each year in the United States, and contributes to over 250,000 deaths. In addition, there are 5.5 million stroke survivors, many with persistent neurological deficits [1].

Presently, the only FDA approved treatment for ischemic stroke is tissue plasminogen activator (t-PA), a thrombolytic drug administered intravenously. However, a major risk of t-PA administration is intracerebral hemorrhage, and the treatment must be given within three hours of stroke onset to maximize effectiveness and minimize the risk of hemorrhage [2].

The incredibly narrow therapeutic window of t-PA in stroke is generally attributed to, among other factors, the high metabolic requirements of brain tissue [3]. When these needs are not met, the tissue is quickly and irreversibly damaged. For this reason, hypothermia, which lowers brain metabolism, has emerged as a potential alternative or adjunct therapy to t-Pa.

Hypothermia has demonstrated neuroprotection in cases of cardiac arrest $[4,5]$. Preliminary results of studies of hypothermia in the setting of acute stroke have also demonstrated the benefits of cooling [3].

Methods of inducing hypothermia are varied. Whole body surface cooling can be induced through through cooling blankets, and/or alchohol [6]. Although these methods are simple to employ, the time to reach target

Manuscript received July 10, 2006.

M. A. Neimark and A. F. Laine are with the department of Biomedical Engineering, Columbia University, New York, NY 10027 USA (phone: 212-854-5996; fax: 212-854-5995; e-mail: al418@ columbia.edu).

A. A. Konstas and J. Pile-Spellman are with the Department of Radiology, Columbia University, New York, NY 10032 USA (e-mail: jp59@ columbia.edu). temperature can exceed 6 hours [6], a time which exceeds the critical therapeutic window of 3 hours. Intravenous cooling catheters can potentially induce hypothermia througout entire body more quickly [7]. However, there remain significant and serious complications associated with systemic hypothermia including infections, arrhythmias, and coagulation disorders [3].

Selective brain cooling (SBC), which circumvents many of the complications of systemic hypothermia, is normally induced with ice packs or cooling caps [8]. Theoretical analyses of surface SBC have revealed that cooling occurs in only the outer layer of brain gray matter [9]. Intracerebral temperature monitoring in surface SBC trials confirmed a very limited effect of this method [10].

One potential method of brain SBC is through intracarotid cold saline infusion (ICSI). In this procedure, cold saline is infused into the internal carotid artery (ICA) via transfemoral catheterization. This method has actually been successfully attempted in cases of cardiac arrest [11]. This method would potentially be much faster than whole body cooling and more effective than surface SBC.

To evaluate the potential of intracarotid SBC, a mathematical hemispheric model of the brain has been developed. Temperature evolution in the brain is modeled via the Pennes bioheat transfer equation [12]. Similar models have been employed to evaluate surface SBC [9] and brain temperature in near drowning situations [13].

\section{METHODS}

\section{A. Hemispheric Brain Model}

The 3D hemispheric brain model (HBM) consisted of 4 layers: white matter, gray matter, bone, and scalp. Each layer was given thermal and physiological constant values, including heat conductivity, heat capacity, density, metabolism, and perfusion, corresponding to the layer's physical and biological properties. In addition, the radii of each of the layers of the HBM were set according to the geometry of an average adult human head.

Each of the layers was implemented on three dimensional grids indexed, in spherical coordinates, by radius from sphere center $(r)$, azimuth angle $(\theta)$, and longitudinal angle $(\phi)$. Fig. 1 demonstrates the implementation of the model.

\section{B. Pennes Bioheat Transfer Model}

Heat transfer through the HBM was based on the Pennes bioheat equation [12], expressed as: 


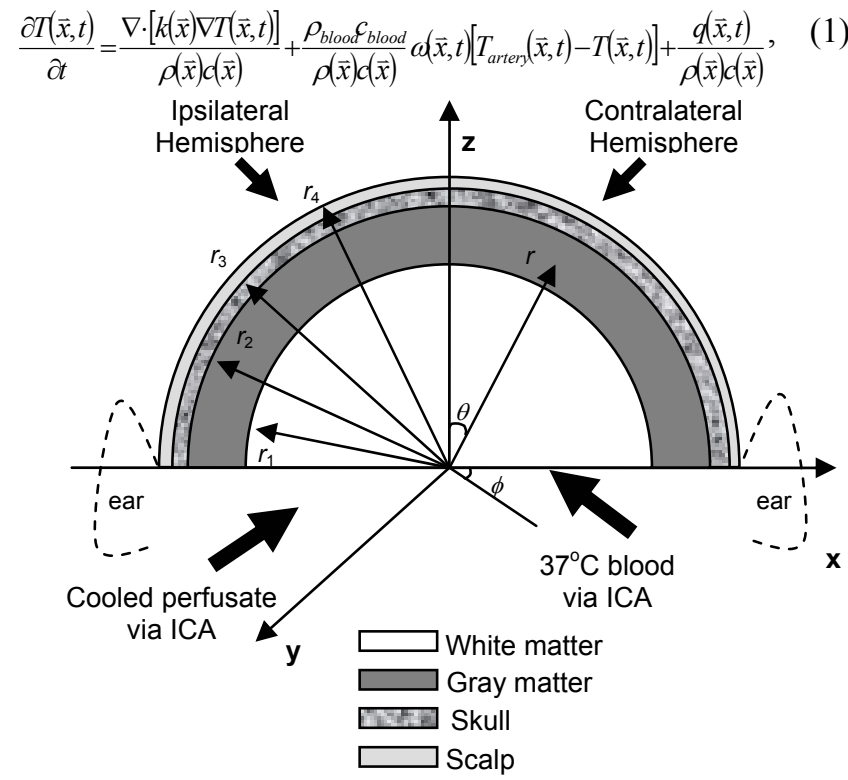

Fig. 1. Coronal view of hemispheric brain model and its tissue layers. 3D grids corresponding to each of the tissue layers are indexed by radius $(r)$, azimuth angle $(\theta)$, and longitudinal angle $(\phi) . r_{1-4}$ are the outer radii of each of the tissue layers. As indicated, the simulations utilized cold saline infusions on only one side.

where $T$ is temperature, $k$ is the tissue thermal conductivity, $\rho$ is density, $c$ is heat capacity, $\omega$ is blood perfusion, $q$ is tissue metabolism, $t$ is the time point, and $\vec{x}$ is the spatial location. The subscript "blood" signifies blood density and heat capacity while the subscript "artery" signifies arterial temperature $\left(37^{\circ} \mathrm{C}\right.$ without cold saline infusion). Tissue variables and parameters lack a subscript.

This 4D partial differential equation was solved using finite differences (three point central differences in space and two point forward differences in time) [14]. In spherical coordinates, the diffusion term of equation (1) is expressed as follows:

$\nabla \cdot[k \nabla T(\vec{x}, t)]=k\left(\frac{\partial^{2} T}{\partial r^{2}}+\frac{2}{r} \frac{\partial T}{\partial r}+\frac{1}{r^{2}} \frac{\partial^{2} T}{\partial \theta^{2}}+\frac{\cot \theta}{r^{2}} \frac{\partial T}{\partial \theta}+\frac{1}{r^{2} \sin ^{2} \theta} \frac{\partial^{2} T}{\partial \theta^{2}}\right) \cdot$

\section{Boundary Conditions}

There are basically three physical boundary conditions implied by this model: the base of the brain (hemisphere), the surfaces between tissue layers, and the outer surface of the scalp.

An adiabatic (i.e. insulated) boundary condition is assumed for the bottom of the brain according to other studies [9]. This is described by the following equation:

$\frac{\partial T}{\partial \theta}=0$

For the boundary between tissue layers, the following equations describe the boundary condition [9].

$k_{1} \frac{\partial T_{1}}{\partial r}=k_{2} \frac{\partial T_{2}}{\partial r}$

$T_{1}=T_{2}$

where the subscripts " 1 " and "2" refer to two different tissue layers.
The following equation describes the boundary condition between the scalp and air $[9,13]$ :

$k \frac{\partial T}{\partial r}=-h_{\text {air }}\left(T-T_{\text {air }}\right)$

where $h_{\text {air }}$ is the heat transfer coefficient between the head and air and is equal to $8 \mathrm{~W} /\left(\mathrm{m}^{2} \cdot \mathrm{K}\right)$ [9]. $T_{\text {air }}$ is the temperature of air $\left(25^{\circ} \mathrm{C}\right)$.

\section{Metabolic and Perfusion Changes with Temperature and Hematocrit}

Hypothermia is known to decrease both metabolism $(q)$ and perfusion $(\omega)$ according to the relations $[9,13,15]$ :

$\omega=\omega_{0} \cdot \alpha^{\beta(T-37)}$

$q=q_{0} \cdot \alpha^{\beta(T-37)}$

where $\omega_{0}$ and $q_{0}$ are baseline perfusion and metabolism for either gray or white matter.

Note that because of coupling of metabolism and perfusion believed to occur in humans and demonstrated to exist in animals [16], the values of $\alpha$ and $\beta$ are assumed to be the same for these two relations.

To determine the values of $\alpha$ and $\beta$, data was pooled together from various human and animal studies of hypothermia [17-19]. This data was fit to (3) using unconstrained nonlinear optimization [20] resulting in values of $\alpha=3.0$ and $\beta=0.08$ (RMSE $=19 \%$ ).

Similarly, there is a nearly linear relationship between brain perfusion and hematocrit described by the relation:

$\omega=\omega_{0} \cdot\left(1-\gamma \Delta_{H C T}\right)$

To determine the value of $\gamma$, data was pooled together from various human studies of normovolemic and "Triple $H$ " hemodilution $[21,22]$. The data was fit to (5) using linear least-squares fitting resulting in a value of $\gamma=2.2$ $($ RMSE $=5.3 \%)$.

Combining (3) and (5) yielded a relationship for combined hematocrit and temperature changes which was used for modeling purposes.

$\omega=\omega_{0} \cdot 3.0^{0.084(T-37)}\left(1-2.2 \Delta_{H C T}\right)$

\section{E. ICA Perfusion Territory}

Since the model involves a unilateral intracarotid saline infusion, there are two regions of significance in the model: the region perfused by the ipsilateral ICA, and the rest of the model (note that the model assumes that the perfusion regions are non-overlapping).

Geometrically, the ipsilateral ICA region occupies only one side of the model (conventionally the right side). Further, the rear $30^{\circ}$ of the ipsilateral side of the brain is perfused by the posterior circulation (i.e. vertebral arteries).

Therefore, the ICA territory of the model is described by: $\left\{(r, \theta, \phi) \mid\left(r<r_{2}\right) \wedge\left[\left(0 \leq \phi \leq 90^{\circ}\right) \vee\left(\left(270^{\circ} \leq \phi \leq 360^{\circ}\right) \wedge\left(0 \leq \theta \leq 60^{\circ}\right)\right)\right]\right\}(11)$

\section{F. Temperature and Hematocrit changes with Infusion}

A cold saline infusion into the intracarotid artery will both cool and hemodilute the blood according to the saline 
infusion rate and the rate of blood flow according to the following two equations:

$$
\begin{aligned}
& T_{p}=\frac{\text { ICA Blood Flow } \cdot 37^{\circ} \mathrm{C}+\text { Saline Flow } \cdot T_{\text {saline }}}{\text { ICA Blood Flow }+ \text { Saline Flow }} \\
& H C T_{p}=\frac{\text { ICA Blood Flow } \cdot \text { HCT }}{\text { ICA Blood Flow }+ \text { Saline Flow }}
\end{aligned}
$$

where $T_{p}$ and $H C T_{p}$ is, respectively, the temperature and hematocrit of the perfusate (cold saline mixed with blood). $H C T$ is the systemic hematocrit.

The ICA blood flow is determined by integrating the perfusion map within the region described by (11):

$$
\text { ICA Blood Flow }=\iiint_{\text {ICATerritory }} \omega d V
$$

The systemic hematocrit, $H C T$, changes with infusion of saline according to the following equation:

$$
\Delta_{H C T}=\frac{p V_{R B C} \Delta V_{I V}}{V_{I V 0}\left(V_{I V 0}+p \Delta V_{I V}\right)}
$$

where $V_{R B C}(2.1 \mathrm{~L})$ is the red blood cell volume, $V_{I V 0}(5 \mathrm{~L})$ is the initial intravascular volume, $\Delta V_{I V}$ is the volume of added saline, and $p$ is the fraction of extracellular body water that is intravascular.

In steady state, $p$ is normally between 0.25 and 0.33 . However, since therapy will take place over short periods of time relative to the time for intravascular volume to reach equilibrium, $p$ should be somewhat higher in practice. To determine a working value of $p,(15)$ was fit with data from hypervolemic hemodilution studies [23, 24] by unconstrained nonlinear optimization [20], yielding $p=0.42$ $(\mathrm{RMSE}=0.014)$.

\section{G. Stroke Model}

An ischemic volume, with both stroke core and ischemic penumbra, was created within the ICA perfusion region, in both gray and white matter, according to the following angle demarcations: Stroke core $\left(\theta=16^{\circ}-54^{\circ} ; \phi=37.5^{\circ}-52.5^{\circ}\right)$; ischemic penumbra $\left(\theta=18^{\circ}-36^{\circ}\right.$ and $54^{\circ}-72^{\circ} ; \phi=15^{\circ}-$ $37.5^{\circ}$ and $52.5^{\circ}-75^{\circ}$ ). The total stroke volume was 136.4 $\mathrm{ml}$ and the volume of the core was $11.87 \mathrm{ml}$.

During ischemia, blood perfusion and metabolic rate in the ischemic core were reduced to $25 \%$ and $30 \%$ of their normal values, respectively. Blood perfusion and metabolic rate were reduced to $40 \%$ and $50 \%$, respectively, in the evolving infarct (ischemic penumbra). These reductions in metabolic rate and perfusion are close to the ones reported in the literature.

\section{RESULTS}

Fig. 2 demonstrates the temperature distribution in a Vshaped trajectory through the brain (passing through the stroke core) after 1 hour of freezing-cold saline infusion at different rates. The simulation demonstrates that the temperature can decrease to as low as $28{ }^{\circ} \mathrm{C}$ at the graywhite matter boundary with an infusion of $50 \mathrm{ml} / \mathrm{min}$.

Fig. 3 demonstrates the temporal temperature profile of a point $\left(r=74.2 \mathrm{~mm}, \theta=22.5^{\circ}\right.$, and $\left.\phi=63^{\circ}\right)$ in the stroke penumbra (the area of the stroke volume most amenable to therapy) over a one hour period, for a variety of freezing- cold saline infusion rates. The temperature decreases most quickly during the first 10 minutes, easily reaching a target hypothermia temperature of $32{ }^{\circ} \mathrm{C}$ [6] for both the 40 and 50 $\mathrm{ml} / \mathrm{min}$ infusion rates. Note a gradual increase in the temperatures after reaching a minimum at $\sim 15$ min caused by hemodilution increasing warm blood flow through the ICA.

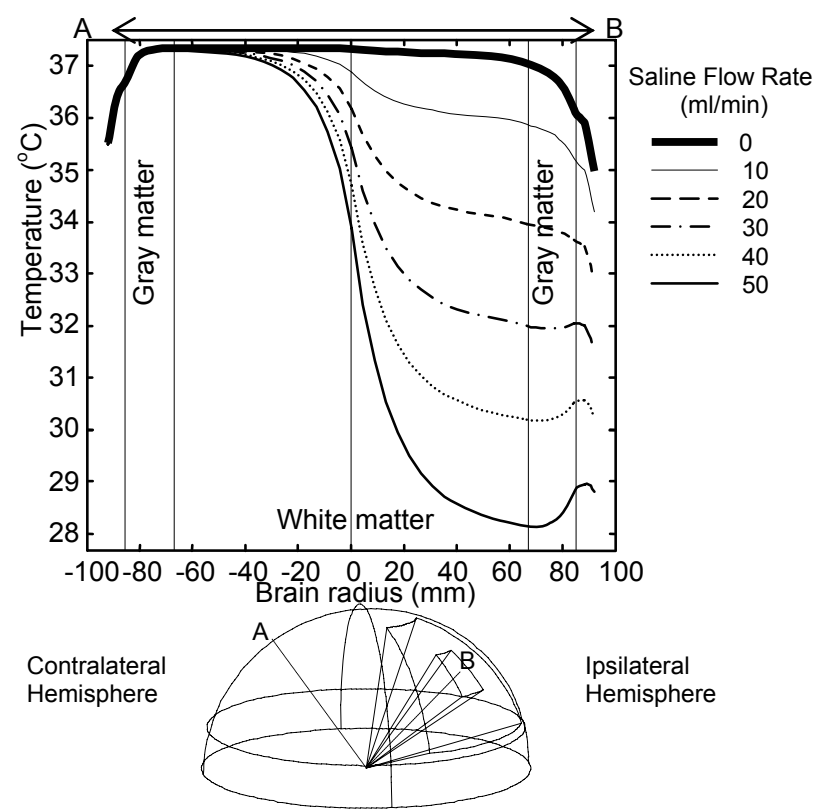

Fig. 2. Radial temperature distribution, $60 \mathrm{~min}$ after different rates of saline infusion in a brain with stroke. Temperature was sampled along line $A B$ (dashed). The V-shaped line $\mathrm{AB}$ starts at a latitude of $45^{\circ}$, descends to the center-base of the brain and ascends back to the same latitude, in a longitudinal plane from $-135^{\circ}$ to $+45^{\circ}$. The longitudinal plane dissects through the posterior circulation territory of the contralateral hemisphere to the anterior territory of the ipsilateral hemisphere, via the center of the brain. Note that line AB passes through the stroke core. Solid bold line $(0 /$ $\mathrm{ml} / \mathrm{min}$ ) represents brain temperature before infusion.

Fig. 4 tracks the hematocrit changes in both the systemic blood and the perfusate which feeds the ipsilateral ICA territory of the brain. Over the course of an hour, the systemic hematocrit always remained above $30 \%$. The hematocrit of the perfusate decreased to a minimum of $25 \%$ after 1 hour of infusion.

\section{CONCLUSIONS}

This study demonstrates the potential of quickly and effectively inducing selective hypothermia in the brain through ICSI. Target temperatures of $\sim 34$ or $\sim 32{ }^{\circ} \mathrm{C}$ can be induced with flow rates of respectively 20 or $30 \mathrm{ml} / \mathrm{min}$. In addition, these temperatures can be quickly induced in less than 10 minutes with an infusion of $40 \mathrm{ml} / \mathrm{min}$.

Although infusion times of 1 hour appear safe, as cardiopulmonary bypass operations have established the safety of hematocrit values in the low 20s [25], the hemodilution effect of this procedure would limit the length of time it could be employed. Other than possibly lengthening the therapeutic window of t-PA or mechanical removal of the thrombosis, this procedure could also be used 
as an adjunct to systemic hypothermia, immediately lowering brain temperature to its therapeutic target while the rest of the body is in its slower process of cooling.

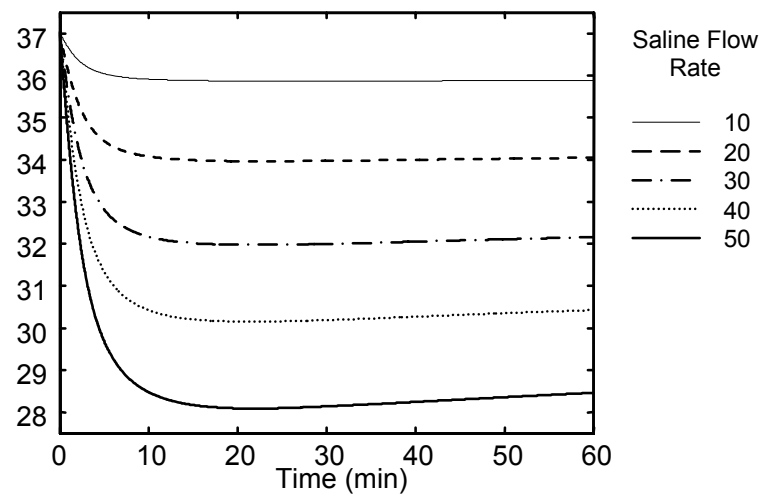

Fig. 3. Brain temperatures in stroke penumbra over one hour sampling period. The sampling point was $r=74.2 \mathrm{~mm}, \theta=22.5^{\circ}$, and $\phi=63^{\circ}$.

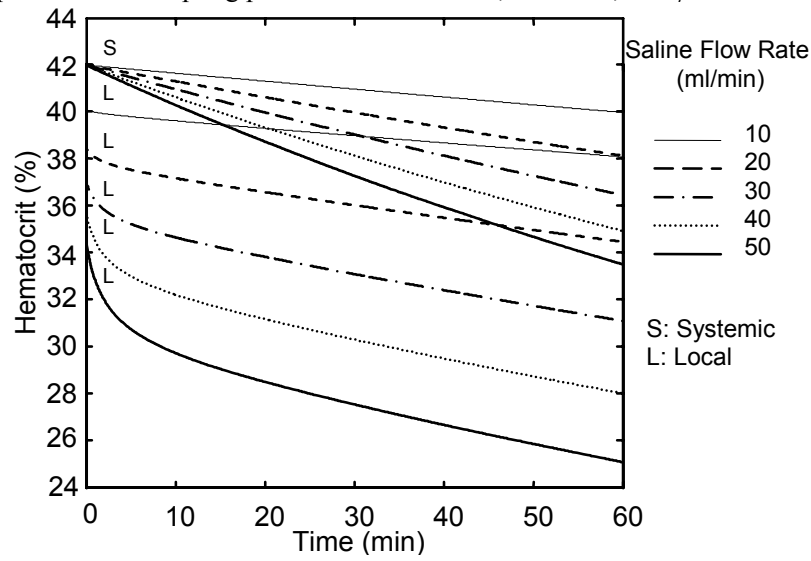

Fig. 4. Systemic and local (i.e. ICA perfusate) hematocrit over the course of a one hour infusion for a variety of saline flow rates.

\section{REFERENCES}

[1] T. Thom, N. Haase, W. Rosamond, V. J. Howard, J. Rumsfeld, T. Manolio, Z. J. Zheng, K. Flegal, C. O'Donnell, S. Kittner, D. LloydJones, D. C. Goff, Jr., Y. Hong, R. Adams, G. Friday, K. Furie, P. Gorelick, B. Kissela, J. Marler, J. Meigs, V. Roger, S. Sidney, P. Sorlie, J. Steinberger, S. Wasserthiel-Smoller, M. Wilson, P. Wolf, and S. American Heart Association Statistics Committee and Stroke Statistics, "Heart disease and stroke statistics--2006 update: a report from the American Heart Association Statistics Committee and Stroke Statistics Subcommittee.[erratum appears in Circulation. $2006 \mathrm{Apr}$ 11;113(14):e696]," Circulation, vol. 113, pp. e85-151, 2006.

[2] "Tissue plasminogen activator for acute ischemic stroke. The National Institute of Neurological Disorders and Stroke rt-PA Stroke Study Group.[see comment]," New England Journal of Medicine, vol. 333, pp. 1581-7, 1995.

[3] S. Schwab, S. Schwarz, M. Spranger, E. Keller, M. Bertram, and W. Hacke, "Moderate hypothermia in the treatment of patients with severe middle cerebral artery infarction.[see comment]," Stroke, vol. 29, pp. 2461-6, 1998.

[4] S. A. Bernard, T. W. Gray, M. D. Buist, B. M. Jones, W. Silvester, G. Gutteridge, and K. Smith, "Treatment of comatose survivors of outof-hospital cardiac arrest with induced hypothermia.[see comment]," New England Journal of Medicine, vol. 346, pp. 557-63, 2002.

[5] M. Holzer, S. A. Bernard, S. Hachimi-Idrissi, R. O. Roine, F. Sterz, M. Mullner, and A. on behalf of the Collaborative Group on Induced Hypothermia for Neuroprotection After Cardiac, "Hypothermia for neuroprotection after cardiac arrest: systematic review and individual patient data meta-analysis.[see comment]," Critical Care Medicine, vol. 33, pp. 414-8, 2005.
[6] D. W. Krieger, M. A. De Georgia, A. Abou-Chebl, J. C. Andrefsky, C. A. Sila, I. L. Katzan, M. R. Mayberg, and A. J. Furlan, "Cooling for acute ischemic brain damage (cool aid): an open pilot study of induced hypothermia in acute ischemic stroke," Stroke, vol. 32, pp. 1847-54, 2001.

[7] M. A. De Georgia, D. W. Krieger, A. Abou-Chebl, T. G. Devlin, M. Jauss, S. M. Davis, W. J. Koroshetz, G. Rordorf, and S. Warach, "Cooling for Acute Ischemic Brain Damage (COOL AID): a feasibility trial of endovascular cooling," Neurology, vol. 63, pp. 3127, 2004.

[8] B. A. Harris and P. J. D. Andrews, "Direct Brain Cooling," in Therapeutic Hypothermia, S. A. Mayer and D. I. Sessler, Eds. New York: Marcel Dekker, 2005, pp. 323-386.

[9] C. Diao, L. Zhu, and H. Wang, "Cooling and rewarming for brain ischemia or injury: theoretical analysis," Annals of Biomedical Engineering, vol. 31, pp. 346-53, 2003.

[10] R. J. Corbett and A. R. Laptook, "Failure of localized head cooling to reduce brain temperature in adult humans," Neuroreport, vol. 9, pp. 2721-5, 1998.

[11] R. G. Selker, S. K. Wolfson, J. C. Maroon, and F. M. Steichen, "Preferential cerebral hypothermia with elective cardiac arrest: resection of "giant" aneurysm," Surgical Neurology, pp. 173-9, 1976.

[12] H. H. Pennes, "Analysis of tissue and arterial blood temperature in the resting human forearm," Journal of Applied Physiology, vol. 1, pp. 93-122, 1948.

[13] X. Xu, P. Tikuisis, and G. Giesbrecht, "A mathematical model for human brain cooling during cold-water near-drowning," Journal of Applied Physiology, vol. 86, pp. 265-72, 1999.

[14] R. Haberman, Elementary Applied Partial Differential Equations. Upper Saddle River, NJ: Prentice-Hall, Inc., 1998.

[15] B. H. Dennis, R. C. Eberhart, G. S. Dulikravich, and S. W. Radons, "Finite-element simulation of cooling of realistic 3-D human head and neck," Journal of Biomechanical Engineering, vol. 125, pp. 832-40, 2003.

[16] A. Iguchi, K. Haneda, S. Sato, and T. Horiuchi, "Determination of safe interval of circulatory arrest from the cerebral metabolic aspect," Tohoku Journal of Experimental Medicine, vol. 149, pp. 191-204, 1986.

[17] R. Jalan, S. W. Damink, N. E. Deutz, A. Lee, and P. C. Hayes, "Moderate hypothermia for uncontrolled intracranial hypertension in acute liver failure.[see comment]," Lancet, vol. 354, pp. 1164-8, 1999.

[18] H. L. Rosomoff and D. A. Holaday, "Cerebral blood flow and cerebral oxygen consumption during hypothermia," American Journal of Physiology, vol. 179, pp. 85-88, 1954.

[19] B. Walter, R. Bauer, G. Kuhnen, H. Fritz, and U. Zwiener, "Coupling of cerebral blood flow and oxygen metabolism in infant pigs during selective brain hypothermia," Journal of Cerebral Blood Flow \& Metabolism, vol. 20, pp. 1215-24, 2000.

[20] R. Fletcher and M. J. D. Powell, "A rapidly convergent descent method for minimization," Computer Journal, vol. 6, pp. 163-8, 1963.

[21] L. Henriksen, O. B. Paulson, and R. J. Smith, "Cerebral blood flow following normovolemic hemodilution in patients with high hematocrit," Annals of Neurology, vol. 9, pp. 454-7, 1981.

[22] T. C. Origitano, T. M. Wascher, O. H. Reichman, and D. E. Anderson, "Sustained increased cerebral blood flow with prophylactic hypertensive hypervolemic hemodilution ("triple-H" therapy) after subarachnoid hemorrhage," Neurosurgery, vol. 27, pp. 729-39; discussion 739-40, 1990.

[23] K. W. Grathwohl, B. J. Bruns, C. J. LeBrun, A. K. Ohno, T. A. Dillard, and H. M. Cushner, "Does hemodilution exist? Effects of saline infusion on hematologic parameters in euvolemic subjects," Southern Medical Journal, vol. 89, pp. 51-5, 1996.

[24] K. D. Stamler, "Effect of crystalloid infusion on hematocrit in nonbleeding patients, with applications to clinical traumatology," Annals of Emergency Medicine, vol. 18, pp. 747-9, 1989.

[25] D. J. Cook, W. C. Oliver, Jr., T. A. Orszulak, R. C. Daly, and R. D. Bryce, "Cardiopulmonary bypass temperature, hematocrit, and cerebral oxygen delivery in humans," Annals of Thoracic Surgery, vol. 60, pp. 1671-7, 1995. 